\title{
Hydroxylation and cation segregation in
}

\section{$\left(\mathrm{La}_{0.5} \mathrm{Sr}_{0.5}\right) \mathrm{FeO}_{3-\delta}$ electrodes}

\section{Supplementary Material}

Dawei Zhang, ${ }^{\mathrm{a}, \#, 1}$ Michael L Machala,,${ }^{\mathrm{a}, \mathrm{b}, \#}$ Di Chen, ${ }^{\mathrm{a} \#, 2}$ Zixuan Guan, ${ }^{\mathrm{c}}$ Hanshi Li, ${ }^{\text {a Slavomir Nemsak, }}{ }^{\mathrm{d}}$ Ethan J. Crumlin, ${ }^{\mathrm{d}}$ Hendrik Bluhm, ${ }^{\mathrm{d}, 3}$ William C. Chueh ${ }^{\mathrm{a}, \mathrm{b}, \mathrm{e}^{*}}$

a Department of Materials Science and Engineering, Stanford University, Stanford, California, 94305, USA.

${ }^{\mathrm{b}}$ Precourt Institute for Energy, Stanford University, Stanford, California, 94305, USA

${ }^{c}$ Department of Applied Physics, Stanford University, Stanford, California, 94304, USA.

d Advanced Light Source, Lawrence Berkeley National Laboratory, Berkeley, California, 94720, USA

e Stanford Institute for Materials and Energy Science, SLAC National Accelerator Laboratory, Menlo Park, CA 94025, USA

${ }^{1}$ Present Address: Department of Material Science and Engineering, University of California San Diego, La Jolla, California, 92092, USA

2 Present Address: The Future Laboratory, Tsinghua University, Beijing, 100084, China

${ }^{3}$ Present Address: Fritz Haber Institute of the Max Planck Society, 14195 Berlin, Germany

\# equal contributions

* Corresponding author: wchueh@stanford.edu 


\section{Supplementary Table}

Table S1. ICPMS results of duplicate thin films of the studied compositions

\begin{tabular}{|c|c|c|}
\hline Film & A/B & Sr/(Sr+La) \\
\hline LSF55 & $1.00 \pm 0.04$ & $0.52 \pm 0.02$ \\
\hline
\end{tabular}

\section{Supplementary Figures}

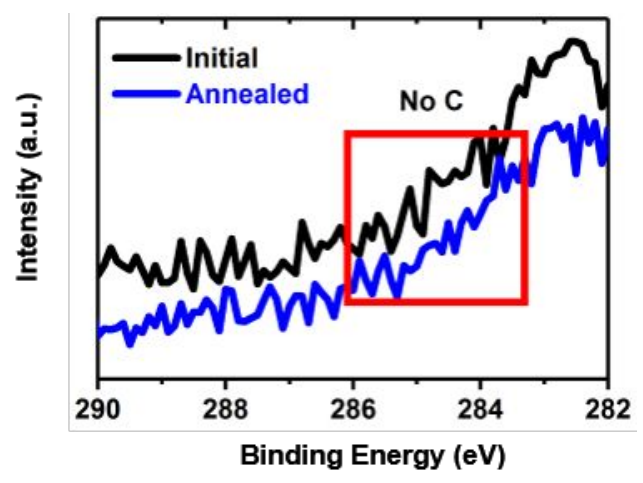

Figure S1. C 1s photoelectron spectra of LSF55 thin film. The electrode was heated up to $650{ }^{\circ} \mathrm{C}$ under open circuit voltage in $200 \mathrm{mTorr}_{2}$.

(a)

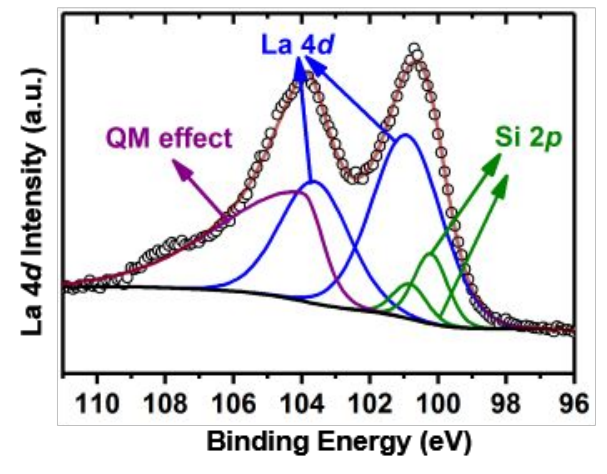

(b)

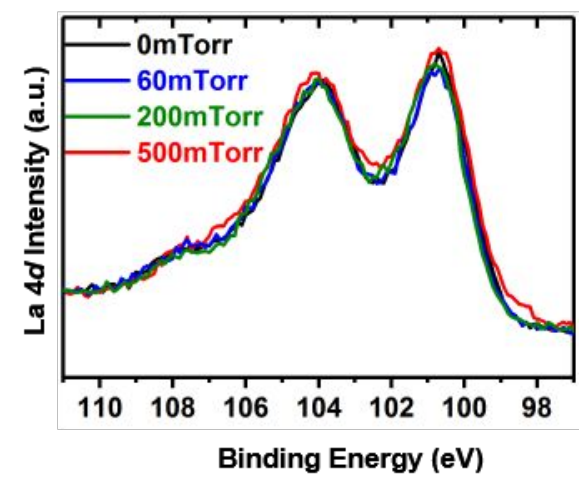

Figure S2. Fitting of La $4 d$ photoelectron spectra with Si impurity level indicated. Time evolution of normalized La $4 d$ under $200 \mathrm{mTorr} \mathrm{O}_{2}+\mathrm{X}$ mTorr $p \mathrm{H}_{2} \mathrm{O}(\mathrm{X}=0,60,200,500)$ at $650{ }^{\circ} \mathrm{C}$. 
X-ray Diffraction (XRD)

Panalytical Xpert PRO was used to collect thin film diffraction patterns (XRD) using $\mathrm{Cu} \mathrm{K} \alpha$ radiation over a $2 \theta$ range of $20^{\circ}$ to $80^{\circ}$ (step size of $0.01^{\circ}$ for $2 \theta$, scan step of $5 \mathrm{sec}$, fixed divergence slit of 1/16", and generator at $40 \mathrm{~mA}$ and $40 \mathrm{kV}$.) The diffraction patterns of LSF55 is shown in Figure S8. Both patterns have the same perovskite structure and peak index. Because SDC has similar lattice parameter asceria. ${ }^{1,2}$

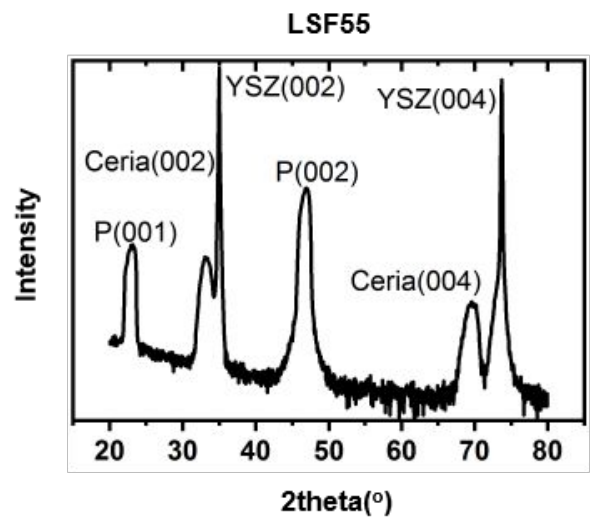

Figure S3. 2theta-omega scan of LSF55.

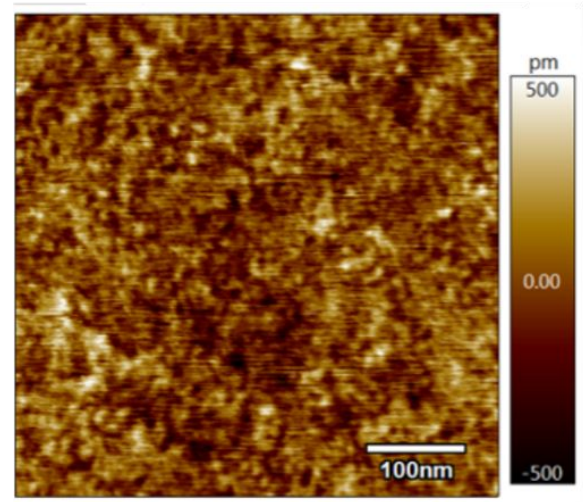

Figure S4. Surface morphology of LSF55 thin film measured by AFM. 
(a)

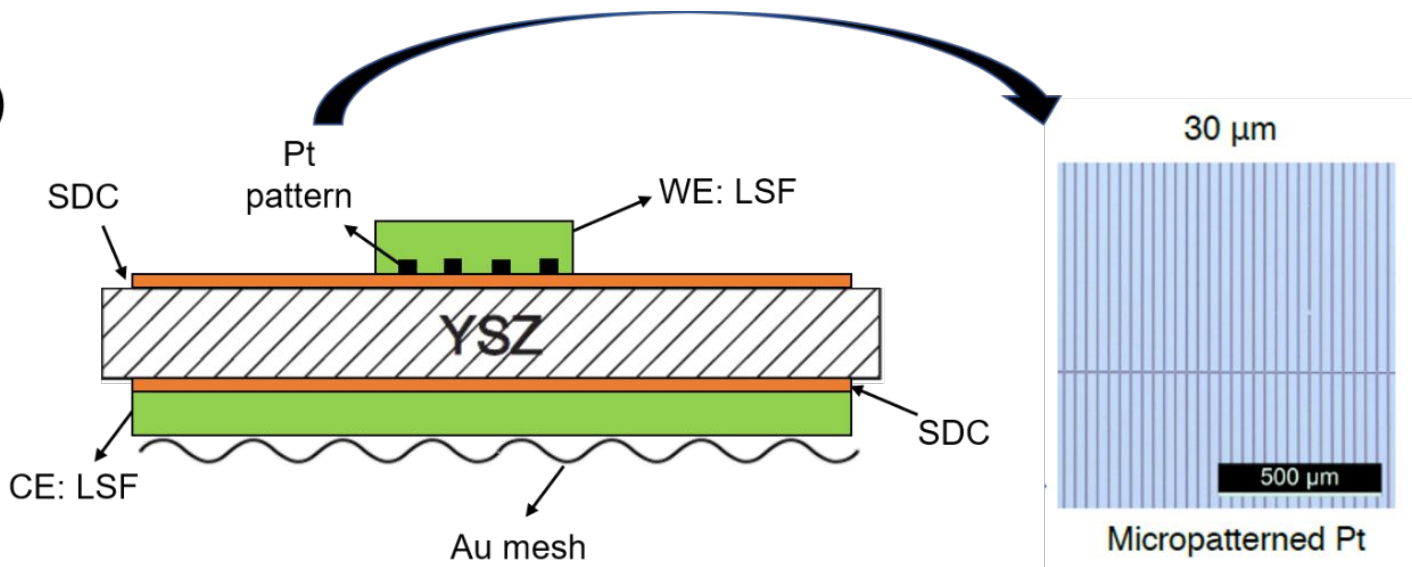

(b)

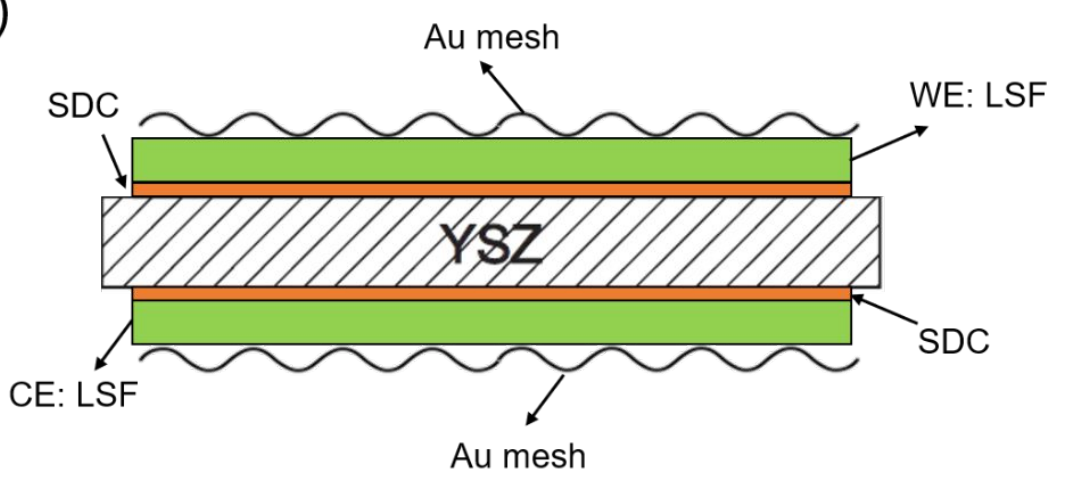

Figure S5 Schematic of (a) APXPS micro-electrode-set up and (b) Large film set-up References:

1 S. Sanna, V. Esposito, A. Tebano, S. Licoccia, E. Traversa and G. Balestrino, Small, 2010, 6, $1863-1867$.

2 D. Chen, S. R. Bishop and H. L. Tuller, J. Electroceramics, 2012, 28, 62-69. 